\title{
Facial nerve pathology in leprosy: searching for the proximal extent of the lesion in facial nerve biopsies
}

\author{
B. M. RICHARD* \& J. M. JACOBS** \\ *Green Pastures Hospital, Pokhara, Nepal \\ **Department of Neuropathology, Institute of Neurology, Queen \\ Square, London WCIN $3 B G, U K$
}

Accepted for publication 31 July 1999

\begin{abstract}
Summary A light and electron microscope study was made of resin embedded facial nerves in three cases of leprosy involving the facial nerve. The patients had irreversible facial nerve palsies and had requested facial reconstruction. No consistent pattern of nerve fibre damage was found. In one case the temporozygomatic was affected, but the cervical branch was normal, suggesting the damage begins distally. In two cases the loss of nerve fibres in the trunk and all branches was similar, and is likely to emanate from damage at a more proximal site. The presence of increased numbers of unmyelinated axons, often in clusters, is evidence of regeneration. These axons probably have the potential to develop into functional myelinated fibres provided that they can innervate a viable distal target such as a muscle graft. These regenerating axons are distal to the stylomastoid foramen suggesting that the most proximal level of involvement of the facial nerve could be intracranial. The finding of a more proximal level of nerve involvement, implies that the misreinnervation seen in partially recovered facial nerve palsies in leprosy, could be due to some regenerating axons being mis-directed at the level of the main trunk bifurcation.
\end{abstract}

\section{Introduction}

Leprosy is a disease of nerves; its pathogenesis is poorly understood. Of the facial nerve branches, the zygomatic branch is reported to be the most frequently affected by leprous infection. ${ }^{1,2}$ Its branches pass through 'fibrous fascial tunnels' ${ }^{3}$ and over the 'bony protuberance of the zygoma', ${ }^{1}$ both probably contributing to its vulnerability. A further factor is its passage through the thin superficial tissue over the zygomatic bone, a region of lowered temperature. ${ }^{2}$

The zygomatic branch of the facial nerve is known to have interconnections of its more distal parts with those of the sensory maxillary division of the trigeminal nerve. ${ }^{1,4}$ Dastur and Antia ${ }^{1,3,5}$ pointed this out following studies correlating facial nerve involvement with

Correspondence to: B. M. Richard, 5 Ledbury Close, Eccleston, St Helens, Merseyside WA10 5NY, UK. 
sensory loss over the malar region, suggesting that leprous infection had spread to the motor nerve from a primary infection of the sensory nerve terminals of the trigeminal nerve.

The site at which the facial nerve is involved is not known, although it is assumed to be the distal zygomatic branch, since palsies are more frequent in the zygomatic region, and there is some histological evidence ${ }^{1,5}$ to support this view. Although evidence for the particular susceptibility of the zygomatic branch is strong, ${ }^{3,6-12}$ a recent study of patients with lagophthalmos ${ }^{9}$ has shown that in over $80 \%$, other facial muscles were involved, suggesting that, on clinical grounds, the zygomatic branch is not uniquely vulnerable.

The cervical branch of the facial nerve might be expected to be frequently involved as it innervates a very superficial panniculus carnosus muscle, the platysma, and is surrounded by cutaneous sensory nerves in the neck which are commonly enlarged. However, most leprologists do not regularly examine the action of the platysma as any functional deficit would be of little clinical relevance. Some believe the cervical branch never to be involved, ${ }^{13}$ while we at Green Pastures Hospital have demonstrated it to be occasionally affected in those with a facial nerve palsy ${ }^{14}$ and probably never as an isolated palsy.

Recent intra-operative electrodiagnostic studies have demonstrated proximal lesions in trunk nerves that appear to the naked eye to be normal. Subsequent intrafascicular neurolysis at this more proximal level has proved to be beneficial. ${ }^{15,16}$

The intention of this study was to establish by electron microscopy the most proximal level at which the facial nerve is affected by leprosy. The possibilities for the site of the irreversible part of the lesion are several: exclusive distal nerve branch disease with failed reinnervation: or more proximal disease but the fibro-osseous tunnels over the zygoma cause such severe compression and subsequent fibrosis preventing nerve regeneration beyond this level: or the irreversible damage could be more proximal, in the main trunk, stylomastoid foramen or middle ear. In our attempt to answer this, we carried out facial nerve biopsies on three selected patients in order to correlate if possible, the histological findings of electron microscopy of the facial nerve with the clinical picture of the patients facial nerve palsy.

\section{Patients and methods}

Leprosy patients requesting reconstruction of a facial deformity caused by a near total facial nerve palsy of more than 4 years (and so considered to be irreversible), were offered a static sling reconstruction for the mouth, and if clinically indicated, a temporalis muscle transfer for lagophthalmos. At the same time, they were asked if they would permit a dissection of the facial nerve for the purposes of a biopsy for medical research. Ethical permission for this study was obtained from the Hospital research resource committee, and the consent of each patient was given after full explanation by a Nepali staff member.

\section{SURGERY}

Under general anaesthetic, the main trunk of the facial nerve was located proximally and the nerve dissected by carrying out a superficial parotidectomy. Once the entire nerve was displayed, from the level of the sternomastoid foramen up to its distal branches entering the musculature of the face (Figure 1), non-functioning branches were biopsied. The patients had a static sling reconstruction of the angle of the mouth using fascia lata strips attached to the malar periosteum. A Johnston type temporalis muscle transfer was used for the lagophthalmos. ${ }^{17,18}$ 


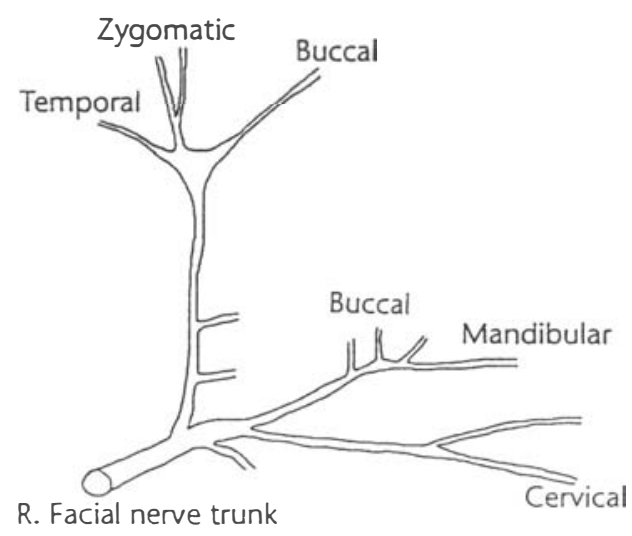

Figure 1. Line drawing of an example of an entire right facial nerve excised from the mastoid foramen to all the branches distal to the superficial parotid gland.

\section{NERVE BIOPSY}

Nerves were held carefully and fixed in $3 \%$ glutaraldehyde in $0.05 \mathrm{M}$ cacodylate buffer and stored at $4^{\circ} \mathrm{C}$.

Semithin and ultrathin sections were prepared for light and electron microscopy. Semithin sections were stained with methylene blue, Azure II and basic fuchsin ${ }^{19}$ and Mycobacterium leprae bacilli when present, are readily visible staining a deep red. $M$. leprae also have a highly characteristic appearance by electron microscopy (EM). Quantitative methods have been described elsewhere ${ }^{20}$ i.e. counting of myelinated fibres and measurement of their diameters, and counting of unmyelinated axons. Control data of the normal buccal branch of the facial nerve are taken from a quantitative study of the facial nerve regenerating through a graft. $^{21}$ Findings are summarized in Table 1.

\section{Results}

CASE 1

SDD; a 67-year-old male, first presented in 1962 with borderline lepromatous leprosy (BL). He had many small red raised skin lesions with sensory neuropathy of the feet. The right ulnar, lateral popliteal and left great auricular nerves were enlarged. He had a right facial nerve paresis with malar and corneal anaesthesia. Facial macules were in reversal reaction with a right lagophthalmos. He had a right temporalis muscle transfer in 1963. He presented in 1994 requesting reconstruction for his facial weakness. On examination he had a right facial nerve lower motor neuron (LMN) paresis. The angle of the mouth drooped, but he could control the lower lip, and pout weakly. He could not show his teeth, and only weakly hold his buccal pouch full of air. His platysma was normal with no paralysis. Transcutaneous electrical stimulation confirmed no function in the zygomatic and temporal branches of the facial nerve and weakness of the buccal and mandibular branches. At operation (April 1994), because the mandibular branch had some residual function, it was decided to give him a static facial sling but not to excise his entire facial nerve. The nerve was dissected from the main trunk to all five named branches. Excision biopsies of his temporo-zygomatic branch $(2 \mathrm{~cm})$, 
Table 1. Qualitative and quantitative description of facial nerve biopsies in three leprosy patients with facial nerve palsies

\begin{tabular}{|c|c|c|c|c|c|c|c|c|c|c|c|c|}
\hline \multirow[b]{2}{*}{ Case } & \multirow[b]{2}{*}{ Nerve } & \multicolumn{2}{|c|}{ Fascicles } & \multirow[b]{2}{*}{$\begin{array}{l}\text { Fascicles } \\
\text { affected }\end{array}$} & \multicolumn{3}{|c|}{ Myelinated fibres } & \multirow{2}{*}{$\begin{array}{l}\begin{array}{c}\text { Unmyelinated } \\
\text { axons }\end{array} \\
\text { Density } \mathrm{mm}^{2} \square\end{array}$} & \multicolumn{2}{|c|}{ Endoneurium } & \multirow[b]{2}{*}{$\begin{array}{l}\text { Inflammatory } \\
\text { cells }\end{array}$} & \multirow[b]{2}{*}{ Comments } \\
\hline & & No. & $\begin{array}{l}\text { Area, } \\
\mathrm{mm}^{2}\end{array}$ & & $\begin{array}{l}\text { Density/ } \\
\mathrm{mm}^{2}\end{array}$ & $\begin{array}{c}\text { Active } \\
\text { degeneration }\end{array}$ & Regeneration & & $\begin{array}{l}\text { Collagen } \\
\text { increased }\end{array}$ & Odema & & \\
\hline \multirow[t]{3}{*}{1} & Temporo-zygomatic & 1 & $0 \cdot 12$ & 1 & 5474 & - & Few & 81,252 & Moderate & - & - & \multirow{10}{*}{$\begin{array}{l}\text { Normal motor } \\
\text { nerve } \\
\text { Nerve architecture } \\
\text { destroyed }\end{array}$} \\
\hline & Cervical & 4 & $0 \cdot 13$ & 4 & 6250 & - & - & $\begin{array}{l}\text { Normal for } \\
\text { motor nerve }\end{array}$ & - & - & - & \\
\hline & Great auricular & $?$ & & $?$ & - & - & - & & $\begin{array}{l}\text { Totally } \\
\text { collagenized }\end{array}$ & - & - & \\
\hline \multirow[t]{7}{*}{2} & Facial nerve trunk & 3 & $0 \cdot 46$ & 3 & 1048 & V. occ & Few & & Mild & - & V. occ. & \\
\hline & Temporal & 2 & $0 \cdot 08$ & 2 & 1705 & - & V. few & \multirow[t]{2}{*}{ Many* } & Mild & - & - & \\
\hline & Zygomatic & 5 & $0 \cdot 06$ & 5 & 1304 & - & V. few & & Mild & - & - & \\
\hline & Mandibular & 1 & $0 \cdot 06$ & 1 & 2150 & - & - & Many & Mild & - & - & \\
\hline & Cervical & 4 & $0 \cdot 08$ & 4 & 1180 & - & V. few & Many & Mild & - & - & \\
\hline & Buccal & 7 & $0 \cdot 34$ & 5 & 5593 & - & $?$ & Many & Mild & - & - & \\
\hline & & & & 2 & 743 & - & V. few & Many & Mild & - & - & \\
\hline \multirow[t]{5}{*}{3} & Facial nerve trunk & 4 & $1 \cdot 05$ & 4 & 209 & Occ & V. few & 23,653 & - & Marked & Numerous & \multirow{5}{*}{$\begin{array}{l}\text { Fascicular area } \\
\text { increased } \\
" \\
" \\
"\end{array}$} \\
\hline & Temporo-zygomatic & 3 & $0 \cdot 86$ & 3 & 255 & Occ & V. few & Many & - & Marked & Numerous & \\
\hline & Mandibular & 1 & $0 \cdot 18$ & 1 & 481 & Occ & V. few & Many & - & Marked & Numerous & \\
\hline & Cervical & 2 & $0 \cdot 36$ & 2 & 306 & Occ & V. few & Many & - & Marked & Numerous & \\
\hline & Great auricular & 8 & $0 \cdot 66$ & 8 & 2265 & - & Many & Few & - & Marked & Numerous & \\
\hline
\end{tabular}




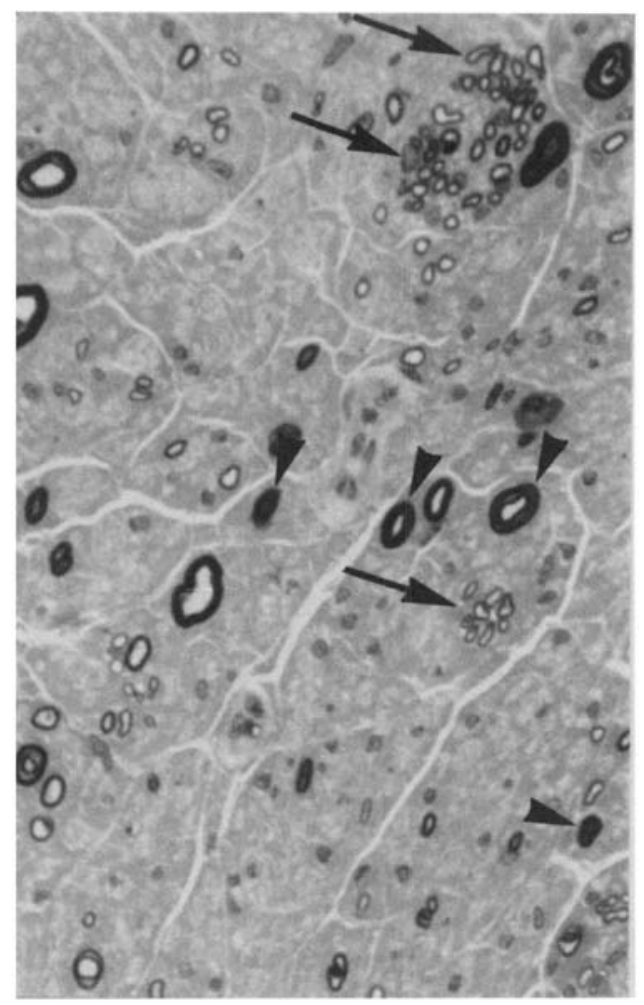

Figure 2. Case 1. Temporo-zygomatic branch of facial nerve. $1 \mu \mathrm{m}$ resin section stained with methylene blue, basic fuchsin, azure II (MBA). There is a reduced density of myelinated fibres; clusters of small regenerating fibres are seen (arrows). A few 'original' myelinated fibres remain; some are very small and atrophic with axons small for myelin sheath thickness (arrowheads). $\times 600$.

and of the (functioning) cervical branch $(3 \mathrm{~cm})$, together with a biopsy of his non-functioning great auricular nerve were taken.

Eighteen months after the operation the patient reported no paraesthesiae in the facial nerve, and no Tinel sign was elicited over the two biopsy sites.

\section{Temporo-zygomatic branch}

The $2 \mathrm{~cm}$ length of nerve was examined at proximal and distal ends. Proximally the nerve consisted of a single fascicle with myelinated fibres distributed in a highly collagenized endoneurium. There were a total of 630 myelinated fibres including a number of regeneration clusters (Figure 2). Some of the larger fibres appeared atrophic, with axons small relative to myelin sheath thickness. The distal end showed a generally similar appearance but more fibres showed axonal atrophy resulting in numbers of unusually small myelinated fibres of $2 \mu \mathrm{m}$ or less. Electron microscopy showed many unmyelinated axons; their density was $81,252 / \mathrm{mm}^{2}$ compared with a mean of $15,660 / \mathrm{mm}^{2} \pm \mathrm{SD} 5470$ in the normal buccal branch of the facial nerve. Many are therefore likely to be regenerating axons. There was no evidence of any ongoing pathology, no inflammatory cells, and no bacilli. 


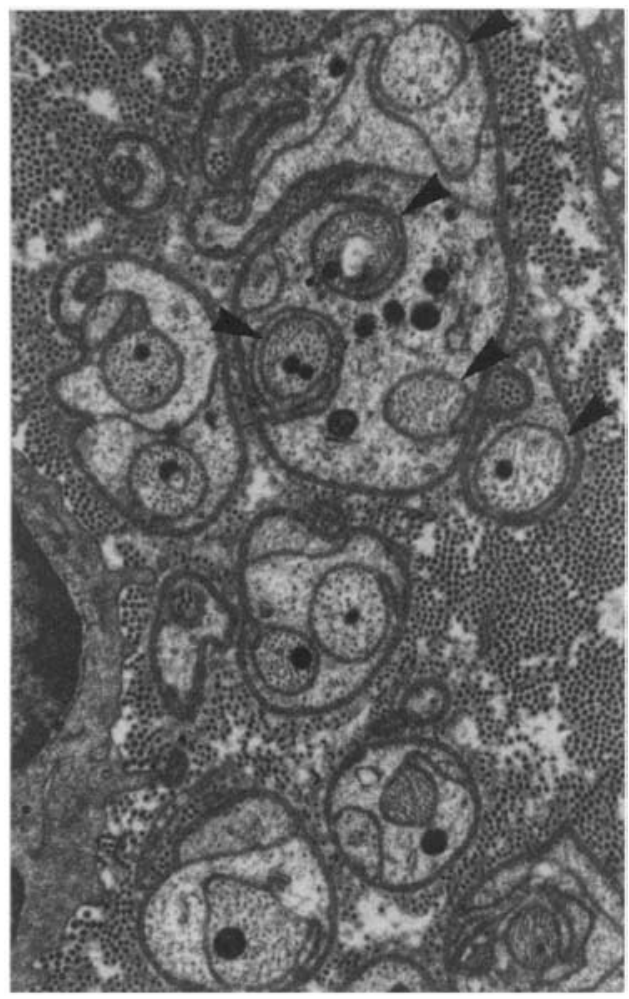

Figure 3. Case 2. Mandibular branch. Electron micrograph showing unmyelinated axons (arrowheads); it is not possible to distinguish regenerated from 'original' unmyelinated axons with certainty. $\times 10,000$.

\section{Cervical branch}

The $3 \mathrm{~cm}$ length of nerve at both proximal and distal ends was composed of four small fascicles each having the normal appearances of a motor nerve, with the majority of myelinated fibres of large size and few small myelinated and unmyelinated axons.

\section{Great auricular nerve}

A very collagenized piece of tissue with nothing in it resembling a nerve. A small group of cells (not bounded by perineurium) was identified by electron microscopy as mainly Schwann cells, most of which were denervated but with an occasional unmyelinated axon.

\section{CASE 2}

PS; a 46-year-old female, first presented in 1988 with borderline tuberculoid leprosy (BT). She had 4-10 hypopigmented and hypoaesthetic, dry macules with raised edges. She had enlarged right ulnar and left lateral popliteal nerves with dry and anaesthetic hands and feet, claw toes and bilateral feet ulcers. Skin smears were negative. She was treated with a course of multibacillary multi drug therapy (MB MDT). She presented again in 1992 with an 
18-month history of a right facial palsy. She had a course of steroids, but with no improvement and was referred with a right lagophthalmos with a $6 \mathrm{~mm}$ palpebral gap and facial palsy.

In 1994, 4 years after the almost total facial palsy developed, there was minimal eyebrow lift, and minimal platysma function. There was no buccal continence for air and no lower lip continence for liquids.

The patient requested surgical correction of her deformity and consented to lose the minimal platysma activity that she had. This allowed us to include the partially functioning cervical branch of her facial nerve in the planned total facial nerve excisional biopsy. In 1994, her entire facial nerve was excised from mastoid foramen to all the branches distal to the superficial parotid gland. She had a temporalis muscle transfer to reconstruct her eye closure and a static sling for the lower lip palsy. Seventeen months after the surgery she continued to note paraesthesiae in the distribution of the right facial nerve. She had a Tinel sign over the proximal nerve stump.

\section{Facial nerve trunk, temporal, zygomatic, mandibular and cervical branches}

These all showed similar appearances. Only in the nerve trunk were there a few inflammatory cells, around epineurial blood vessels. In all nerves there was marked loss of myelinated fibres (Table 1) with densities varying from $1048-2150 / \mathrm{mm}^{2}$. Some of the remaining fibres were atrophic; there were no regeneration clusters. Electron microscopy (EM) showed many bands of Büngner, i.e. denervated Schwann cell processes indicating earlier myelinated fibre degeneration. The numbers of unmyelinated axons (density $54,646 / \mathrm{mm}^{2}$ ) were much greater than in a normal motor nerve (Figure 3) (see Table 1) and many are therefore assumed to be regenerating.

\section{Buccal branch}

A nerve made up of seven fascicles; five fascicles had a near normal density of myelinated fibres (Table 1) although with an abnormal fibre size distribution; compared with a control buccal nerve there was a shift to the left, with increased numbers of small fibres but fewer large fibres. Measurement of myelin sheath thickness showed many fibres to have inappropriately thin myelin sheaths, consistent with being regenerated.

EM of a fascicle well populated with myelinated fibres showed an occasional band of Büngner indicating earlier loss of a few myelinated fibres. Many unmyelinated axons were present. In a severely affected fascicle there were many bands of Büngner, and unmyelinated axons were numerous. The area of the parent facial nerve trunk was $0.46 \mathrm{~mm}^{2}$ and it contained 477 myelinated fibres; the total number of myelinated fibres in all of the branches was 1707 in a total area of $0.62 \mathrm{~mm}^{2}$; this disparity is discussed later.

\section{CASE 3}

MDP, a 64-year-old male, first presented in 1986 with multiple enlarged peripheral nerves, a new total left LMN facial nerve palsy and loss of sensation over the chin and left ear, associated with a fever. He had a swollen and red skin patch over the left mid-face. He had also lost some movement and sensation in his tongue. The tongue and skin sensory changes all reversed but the facial palsy remained. He was noticed to have a single hypoanaesthetic 
patch on his back. There were no other cardinal signs of leprosy. A smear was negative and leprosy serology inconclusive. He was considered to be a case of multibacillary borderline tuberculoid leprosy (MB BT) in reversal reaction and treated with MDT for 24 months. His facial palsy recovered well after a course of steroids and he was left with a lagophthalmos and reduced corneal sensation. However, he returned in 1991 with a left facial nerve palsy again and this time it did not respond to steroids.

On examination in 1995, he was noted to have a complete left LMN facial nerve palsy with $6 \mathrm{~mm}$ lid gap, small corneal ulcer, previous medial tarsorraphy and normal trigeminal dermatome sensation. Clinically, there was a completely paretic left platysma.

At operation (1995), he had a complete dissection of the facial nerve for excision biopsy and a temporalis muscle transfer for lagophthalmos. The great auricular nerve was also biopsied.

Eight months later, he returned for a facial sling procedure (something that he had refused earlier) and he was noted to have a positive Tinel sign over his left facial nerve stump.

\section{Facial nerve trunk}

All four fascicles showed a similar appearance with marked endoneurial oedema causing the fascicular areas to be greatly increased in size (Table 1, compare sizes of branches with those of case 2); endoneurial collagen was not increased. There was marked loss of myelinated nerve fibres; the debris of many quite recently degenerated myelinated fibres still remained. The few myelinated fibres present were very small, occasionally in clusters, and were probably regenerating fibres. Each fascicle was infiltrated by inflammatory cells often grouped around endoneurial blood vessels. The cells were mononuclear (macrophages and lymphocytes), but no foam cells. No organisms were seen. No inflammatory cells were present in the epineurium, and the perineurium appeared normal. Electron microscopy showed bands of Büngner signifying earlier degeneration of myelinated fibres. The density of unmyelinated axons (Table 1) was somewhat greater than that of a normal motor nerve, presumably due to regeneration.

\section{Temporal-frontal, zygomatic, cervical, buccal/mandibular branches}

These had appearances generally similar to those of the nerve trunk.

\section{Great auriciular nerve}

This nerve consisted of eight fascicles, each with a moderate population (see Table 1) of thinly myelinated fibres, often in clusters and identified as regenerated fibres. EM confirmed the presence of regenerating myelinated fibres. Banding of Schwann cell processes associated with unmyelinated axons suggests loss of some of the 'original' unmyelinated axons. No bacilli were seen in any nerve by light or electron microscopy. A number of plasma-like cells often with a basal lamina, previously described in leprosy, ${ }^{22}$ were observed.

\section{Discussion}

There is one previous paper in the literature documenting histology of the facial nerve in leprosy. ${ }^{5}$ The study was of 11 facial nerves, where 10 had a biopsy of only the most peripheral 
branches of non-functioning temporo-zygomatic branches (lagophthalmos), and one biopsy was of a whole, non-functioning facial nerve (F11). The histology was by light microscopy and found evidence of leprosy bacilli in only two of the 11 cases. The findings of fibrosis were severe in the orbicularis oculi nerve endings and less severe in the distal temporo-zygomatic branches. In the one total nerve biopsy, there was a well preserved trunk and proximal nerve with worsening fibrosis into the temporo-zygomatic branch. No acid-fast bacilli were found.

EXTENT OF FACIAL NERVE DAMAGE

There was a generally even distribution of pathology in the various facial nerve branches examined in case 3 (which showed evidence of severe and relatively recent myelinated fibre degeneration), and also in case 2 (with the exception of the buccal branch), with fibre loss at a later stage. These cases do not support the suggestion that the zygomatic branch is selectively involved. It seems likely that nerve fibre degeneration begins more proximally than at the levels examined here. We do not know whether there is more uniform involvement of other facial nerve branches in patients who only have lagophthalamos clinically. Proximal trunk involvement could be the explanation of Ranney's observation ${ }^{11}$ of mis-reinnervation of the facial nerve in patients with a severe facial palsy that later recovers to a large extent. These patients have voluntary co-contractions of unrelated facial muscles and co-contractions associated with the reflex act of blinking (blink bursts) in muscles that do not normally contract in the blink reflex. The mechanism of mis-reinnervation could be regenerating axons in the proximal trunk entering the wrong branch at the main bifurcation or collateral sprouting from non-involved axons into adjacent empty myelin sheaths. ${ }^{23}$

The appearance of the buccal nerve is difficult to explain. It is the only nerve in which there are marked differences from one fascicle to another, some having very few, but others having many myelinated fibres. The origin of these myelinated fibres is puzzling, because their numbers are greater than those in the parent nerve trunk which seems to imply that some originate from another source. They do not have the size distribution of a normal motor nerve and are almost certainly regenerated fibres although none are in clusters, usually a recognized feature of regenerating myelinated fibres. Although within the normal range of total fascicular area for the buccal branch, ${ }^{21}$ the number of fascicles in the nerve was greater than that seen normally, so the possibility that all fascicles do not derive from the parent facial nerve must be considered. Variations in the anatomy of the facial nerve have been described ${ }^{24}$ and this patient may be one of the few (3\%) in which the facial nerve has two main trunks, the minor (which may be missed) contributing to the buccal branch.

The cervical nerve appeared normal in case 1 and clinically, platysma function was normal. In case 2 the nerve showed similar marked pathological changes to those seen in its other facial nerve branches, and clinically there was minimal platysma function; the apparent sparing of this nerve $\mathrm{e}^{13}$ is not confirmed.

Palpable or macroscopic thickening of a nerve is an important indicator of nerve involvement in leprosy, but it should be noted that there was no evidence of nerve swelling in the cervical or any other of the affected nerves in case 2. Clearly, the condition of a nerve cannot be judged solely on external appearances.

EVIDENCE OF LEPROSY INFECTION

The absence of any evidence of leprous infection in case 1 and only minimal evidence of 
inflammatory cell infiltration in the most proximal nerve examined in case 2 may reflect the late stage of the disease when the biopsies were taken. MDT treatment was begun 16 years ago in case 1 and 4 years ago in case 2 . In case 3 the treatment began 9 years ago, but the patient presented with a new facial palsy just 4 years before this biopsy, and inflammatory cells remain, suggesting that this neuropathy is directly caused by leprosy, perhaps associated with a change in the patient's immunological status. No bacilli were seen nor were any identified in any of the nerves from other patients. In none of the cases was there evidence of thickening of the perineurium, a change frequently noted in lepromatous leprosy. ${ }^{25}$

In case 1 , the two motor nerves examined showed very different appearances, the temporo-zygomatic nerve being markedly affected while the cervical nerve appeared normal. This would lend some support to Dastur's suggestion of zygomatic nerve involvement originating through the infection of sensory branches of the maxillary nerve. The temporo-zygomatic nerve contained over 600 myelinated fibres, many identified as regenerating. However, axonal atrophy was noted in many of these fibres, a change consistent with eventual loss of the distal target perhaps due to atrophy of the associated muscle (also exemplified in a permanent axotomy $\operatorname{model}^{26}$ ). The total destruction of the great auricular nerve is consistent with a severe leprous lesion.

In all motor nerves in cases 2 and 3 (with the exception of the buccal nerve in case 2) the pathology was generally evenly distributed both throughout the facial nerve branches and between the fascicles of these nerves. If there is any element of compression involved in the pathogenesis of the lesions, it would have to be operating at levels more proximal than those examined in this study.

\section{REGENERATION}

The presence of unmyelinated axons in excess of normal in affected motor nerves in cases 1 , 2 and 3 was evidence of regeneration; however, there was little further maturation into myelinated fibres and when this occurred only a few, small fibres were seen. This somewhat resembles the appearance of nerves examined in a study of nerve grafts in facial palsy ${ }^{21}$ in which large numbers of unmyelinated axons regenerated from a (motor) branch of the facial nerve into a nerve graft which was unconnected at its distal end. Myelinated fibres were few in number and invariably small in size. The appearances in the leprous nerves possibly reflect a similar situation of axons capable of regeneration, but failing to mature into myelinated fibres because of the absence of stimulus provided by a distal target. Presumably in the leprosy patients, there is atrophy of the associated muscles after long-term denervation. In the nerve graft study, ${ }^{21}$ examination of grafts after distal connection to a grafted muscle (which became functional a few months later) showed large numbers of regenerated myelinated fibres of considerable size. This demonstrates that the unmyelinated axons have the potential to develop into myelinated fibres once they become functional. In the leprosy patients, it raises the possibility of a free gracilis muscle graft to the face for a patient with a complete irreversible facial palsy, with anastomosis of the gracilis nerve to the proximal facial nerve trunk.

A previous morphological study of facial nerves injured during surgery (and examined before faciohypoglossal anstomosis) showed that although some endoneurial fibrosis had occurred this was not sufficient to prevent regeneration even after facial palsy of up to 7 years duration. ${ }^{27}$ In the present study, endoneurial fibrosis was seen at its most extreme with total loss of great auricular nerve architecture in case 1 , and to a much milder degree in the 
temporo-zygomatic branch of the same patient; however, in other nerves the extent of fibrosis was probably not sufficient to compromise regeneration.

Clinically, a Tinel sign was elicited over biopsy sites in cases 2 and 3, suggesting the presence of regenerating axons in a neuroma.

The situation in sensory (great auricular) nerves is different. In case 1, there was total destruction of the great auricular nerve, an appearance consistent with a severe leprous lesion; in case 3, there was regeneration of myelinated fibres, suggesting successful distal connection with sensory targets presumably in the skin.

\section{Acknowledgements}

J. M. J. would like to thank Miss Hilary Ayling for excellent technical help and Mr Steve Durr for photography.

\section{References}

${ }^{1}$ Dastur DK. Pathology and pathogenesis of predilective sites of nerve damage in leprous neuritis. Neurosurg Rev, 1983; 6: 139-152.

2 Reichart PA, Srisuwan S, Metah D. Lesions of the facial and trigeminal nerve in leprosy-an evaluation of 43 cases. Int J Oral Surg, 1982; 11: 14-20.

3 Antia NH, Divekar SC, Dastur DK. The facial nerve in leprosy I. Clinical and operative aspects. Int J Lepr, 1966; 34: 103-117.

4 Williams PL. Gray's anatomy. Edinburgh: Churchill Livingstone, 1995; 1243-1248.

5 Dastur DK, Antia NH, Divekar SC. The facial nerve in leprosy. 2. Pathology, pathogenesis, electromyography and clinical correlations. Int J Lepr, 1966; 34: 118-137.

6 Courtright PD. Defining the magnitude of ocular complications from leprosy: problems of methodology. Int $J$ Lepr, 1988; 56: 566-573.

${ }^{7}$ Hogeweg M, Udaya Kiran K, Suneetha S. The significance of facial patches and type I reaction for the development of facial nerve damage in leprosy. A retrospective study among 1226 paucibacillary leprosy patients. Lepr Rev, 1991; 62: 143-149.

${ }^{8}$ Kumar B, Yande R, Kaur I, Mann SBS, Kaur S. Involvement of palate and cheek in leprosy. Ind J Lepr, 1988; 60: 280-283.

9 Lubbers WJ, Schipper A, Hogeweg M, Soldenhoff DR. Paralysis of facial muscles in leprosy patients with lagophthalmos. Int J Lepr, 1994; 62: 220-224.

10 Lubbers WJ, Schipper A, Hogeweg M, Soldenhoff DR. Eye disease in newly diagnosed leprosy patients in eastern Nepal. Lepr Rev, 1994; 65: 231-238.

11 Ranney DA. The prevalence and consequences of mis-reinnervation in facial neuritis. Int J Lepr 1974; 42: 316322.

12 Udaya Kiran K, Hogeweg M, Suneetha S. Treatment of recent facial nerve damage with lagophthalmos, using a semistandard steroid regimen. Lepr Rev, 1991; 62: 150-154.

13 Crawford CL, Hobbs MJ. Why is the cervical branch of the facial nerve not enlarged in leprosy? J Anat, 1994; 184: $188-188$.

14 Richard BM, Corry PR. The cervical branch of the facial nerve in leprosy. Int J Lepr, 1997; 65: 170-177.

15 Turkof E, Tambwekar S, Mansukhani K, Millesi H, Mayr N. Intraoperative electroneurodiagnostics to detect a second granuloma in the cubital area of the median nerves affected by leprosy: a new approach to prevent incomplete surgery. Int J Lepr, 1995; 63: 409-416.

16 Turkof E, Tambwekar S, Mansukhani K, Millesi H, Mayr N. Intraoperative spinal root stimulation to detect most proximal site of leprous ulnar neuritis. Lancet, 1994; 343: 1604-1605.

17 Warren G. Facial palsy—a leprosy surgeon's viewpoint. Aust NZ J Opthalmol, 1990; 18: 257-266.

18 Soares D, Chew M. Temporalis muscle transfer in the correction of lagophthalmos due to leprosy. Lepr Rev, 1997; 68: $38-42$.

19 Waters MFR, Jacobs JM. Bailliere's clinical neurology. London Bailliere Tindall, 1996; 171-197.

${ }^{20}$ Richardus JH, Finlay KM, Croft RP, Smith WCS. Nerve function impairment in leprosy at diagnosis and at completion of MDT: a retrospective cohort study of 786 patients in Bangladesh. Lepr Rev, 1996; 67: 297-305. 
21 Jacobs JM, Laing JHE, Harrison DH. Regeneration through a long nerve graft used in the correction of facial palsy. A qualitative and quantitative study. Brain, 1996; 119: 271-279.

22 Humphrey CD, Pittman FE. A simple methylene blue-azure II-basic fuchsin stain for epoxy-embedded tissue sections. Stain Technol, 1974; 49: 9-14.

23 Lundborg G, Zhao Q, Kanje N, Danielsen N, Kerns JM. Can sensory and motor collateral sprouting be induced from intact peripheral nerve by end-to-side anastomosis? J Hand Surg 1994; 19B: 277-282.

${ }^{24}$ Dyck PJ, Nukada H, Lais AC, Kames JL. Peripheral neuropathy. Philadelphia: WB Saunders, 1984; 666-690.

${ }^{25}$ Croft RP, Richardus JH, Smith WCS. The effectiveness of corticosteroids in the treatment of long-term nerve function impairment. Lepr Rev, 1997; 67: 342-343.

26 Jacobs JM, Love S. Quantitative and qualitative morphology of human sural nerve at different ages. Brain, 1985; 108: 897-924.

27 Buckley G, Felix H, Fisch U. Faciohypoglossal anastomosis: does the morphology of the facial nerve affect the functional result? Skull Base Surg, 1994; 4: 193-201. 